\title{
When Three's a Crowd: \\ How social structure affects the creation of organizational codes in triads ${ }^{*}$
}

\author{
Özgecan Koçak (ozgecan.kocak@emory.edu) \\ Massimo Warglien (warglien@unive.it)
}

Communication codes shared among members of an organization facilitates coordination across sub-units. Yet, if groups interact separately, they will each develop a specialized code. Using laboratory experiments, we compare the process of code emergence in transitive and cyclical triads. We find that transitive structures hinder dyadic coordination at the start, in particular for groups consisting of strangers. Our findings suggest that the coordination difficulties in transitive triads may be explained by the difficulty to establish a behavioral common ground due to the asymmetry of such structure. These coordination problems are transient - groups of different structures end up with the same average communication performance if given sufficient time. However, there remain lasting differences in the code: transitive groups of strangers are more likely than cyclical groups to have multiple dyadic codes, which are less efficient than group level codes.

\section{Introduction}

Very often, organizations rely in their internal communication on idiosyncratic "codes" (Arrow 1974), specialized languages tailored to their activities and coordination needs that allow more efficient communication than ordinary natural language. Indeed, the phenomenon is not peculiar just to organizations: social groups tend to develop their own jargons, professions develop their own terms of art, and even during a single conversation speakers tend to develop "conceptual pacts" (Brennan and Clark 1996) that reduce the fundamental indeterminacy of natural lexicon (Ludlow 2014) and allow to establish mutual understanding (Clark and Wilkes-Gibbs 1990, WilkesGibbs and Clark 1992). Organizational codes are from this point of view a special case of a broader phenomenon of lexical specialization in linguistic communication.

While a specialized code increases the efficiency of communication between agents that share it, it may have the opposite effect on their coordination with agents that are not socialized into it. For instance, small groups of agents that are left to develop independently specialized codes experience loss of coordination and efficiency in communication when combined into larger groups (Weber and Camerer 2003). Organizational economics has identified the same trade-off through two different (and complementary) perspectives. Theory of optimal design of codes finds

\footnotetext{
*We thank participants at Carnegie School of Organizational Learning Conference in 2016 and MIT Nano-Conference on the Emergence of Categories and Shared Mental Models in 2018 for comments. The study was funded through TUBITAK (Program 1001, Project \# 115K163), O. Kocak received support from TUBA (GEBIP-2014), and M. Warglien was funded through the COPE program supported by a Sapere Aude grant from the Danish Research Council for Independent Research (FSE). Bager Akbay wrote the software code used in the experiments. Zeynep Erden Bayazit, Afşar Yegin, and Yunis İsmayıl assisted with the administration of experiments. We are grateful for their contributions.
} 
steeply decreasing returns to dialect variety. Even with multiple speakers, the optimal code is the code that would prevail if there was only one speaker communicating all the events (Crémer, Garicano, and Prat 2007). Approaching codes as equilibrium solutions to coordination problems, however, concludes that a code is not necessarily unique for an organization (Wernerfelt 2004). Multiple codes, some of which are inefficient, may be supported in equilibrium, depending on the relative importance of coordination within and across groups.

Economic and managerial perspectives emphasize advantages of specialization for local coordination as a reason that may inhibit the creation of a common code. However, other factors may also be relevant. One important insight comes from sociology: the development of solutions to coordination problems is embedded in the nature of relations among agents (Granovetter 1985 , Leifer 1991). The difficulty of creating a common code in an organization may thus be related to the difficulty to create coherent and harmonious systems of relations out of lower level ones. This difficulty can arise already at the simplest level of combining dyadic relations into triadic ones. Simmel (1950: 136) has for example suggested that "it is usual for just such finely tuned combinations of three at once to result in three parties of two persons each, and thus to destroy the unequivocal character of the relations between each two of them."

A third, complementary perspective, based on a closer analysis of the inner working of human language in interaction, illustrates the embedding of codes in relationships. Students of linguistic interaction have shown that a common understanding is achieved through an interactive process of grounding, or the construction of a common ground between communicating agents (Clark 1996, Brennan and Clark 1996). Grounding is a collaborative (and costly) process through which participants to a conversation establish a set of common knowledge, beliefs and assumptions in order to reach an agreement on how linguistic expressions map to objects and events. Grounding is made possible by conversational rules and conventions that are rooted in dyadic conversation (Clark and Schaefer 1989). Their extension to triads is a problematic process, as dyadic agreements have to be transmitted and recreated within the triad (Wilkes-Gibbs and Clark 1992, Weber and Camerer 2003, Galantucci et al 2012) - one might think of it as the difficulty of harmonizing bilateral bargaining agreements till they converge into a trilateral solution. Even larger groups are eventually able to resolve clashes between dyadic codes and settle on a shared group level code if individuals interact with every other individual as in a complete digraph over many rounds of interaction (Garrod \& Doherty 1994, Fay et al 2008, 2010). This level of interaction may not be feasible in most organizations, however.

Prior work thus points to a dilemma: A common communication code facilitates coordination across groups. Yet, if groups interact separately, they will each develop a specialized code. This dilemma can be seen as an instance of the trade-off that all organizations face in dividing and integrating their members' actions. This raises the possibility that it can be managed through organization design. Are some social structures more conducive to creation of a common code than others? None of the prior experimental work has addressed this question. Given that human interaction is typically structured in more or less stable relationships, whether in formal organizations or in informal groups, this remains an important question for investigation.

We examine the effect of social structure on the process of code emergence by comparing the outcomes of conventional matching games played by dyads (Krauss and Glucksberg 1977, Clark and Wilkes-Gibbs 1986) in two distinct triadic configurations. Groups of three individuals (i.e. three dyads) played dyadic matching games for which they were rewarded at the group level, 
based on speed and accuracy of communication. The three dyads in each group were in either a transitive or a cyclical configuration (Holland and Leinhardt 1970). This allowed us to examine the effect of relational structure of dyads, in particular, the effect of transitive relations, which are closely related to hierarchical structures (Bunderson et al 2016), on the emergence of codes.

The effect of structure can be expected to be contingent on prior common ground. Even in dyads, establishing common ground requires to coordinate both content and process (Clark and Brennan 1996). This means that grounding may be affected by how much participants share interaction rules - and are aware of it. Furthermore, friends share personal common ground (Clark 1996). Therefore, in order to understand how familiarity may affect the grounding process we have also recorded social relations between subjects pre-existing the experiment.

We find that transitive structures hinder dyadic coordination at the start, in particular for groups consisting of strangers. These coordination problems are transient. Groups of different structures end up with the same average communication performance if given sufficient time. However, there remain lasting differences in the code, with transitive groups of strangers having more dyadic codes than cyclical groups. We also find these dyadic codes to be less efficient than group level codes for coordination.

\section{The experiment}

The experiment consisted of dyadic matching games played by three dyads in a triad. Matching games consist of one individual in the role of 'message sender' describing an image to another, the 'message receiver', who tries to find the correct image. It is well established in prior studies that dyads develop specific labels for describing images, that is, a lexical code, after repeated games (Krauss and Glucksberg 1977, Clark and Wilkes-Gibbs 1986). This is true whether individuals take turns playing both roles or whether the roles remain fixed and asymmetric throughout the interaction.

In order to examine how structure influences the emergence of code, we created groups in one of two triadic configurations (Figure 1). The first configuration is characterized by transitive relations, with the three agents in different relational positions (henceforth, " $\mathrm{T}$ "). The second is an intransitive configuration, characterized by a cyclical relational structure in which all agents have the same relational position and the same role in each dyadic relation (henceforth, " $\mathrm{C}$ "). It is an appropriate comparison to the transitive triad because it consists of the same number and kind of dyadic relations. The only difference between them is the direction of one of the ties.

Participants were seated at terminals where they could not see each other and could only communicate through headsets. In each game, one person played the role of message sender, trying to communicate one of sixteen images shown on their screen. The other person in the dyad played the role of message receiver, trying to guess the correct image. The third person in the group, the bystander, was allowed to hear the focal dyad and see the images picked by the message receiver in the 'transparent communication' condition but not in the 'private communication' condition. Each game continued until the correct image was identified by the receiver. 
Figure 1. Triadic configurations studied

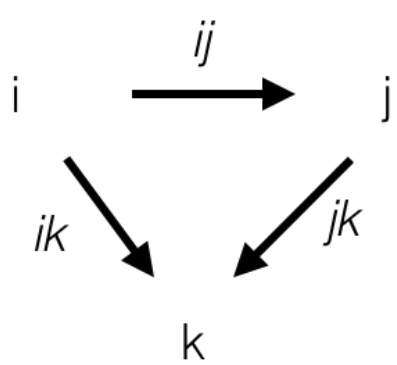

Transitive $\left(\right.$ O30T* $\left.^{*}\right)$

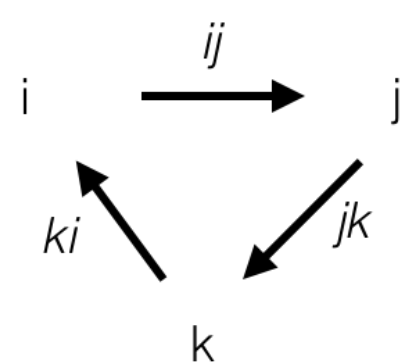

Cyclical $\left(030 C^{*}\right)$

*'030' stands for 0 Mutual, 3 Asymmetric, and 0 Null ties in Holland and Leinhardt's (1970) 'MAN' nomenclature for the triadic isomoporphism classes. "T" stands for transitive, " $\mathrm{C}$ " for cyclical. We use " $\mathrm{T}$ " and " $\mathrm{C}$ " as shorthand throughout the text.

The order of dyads and images were determined randomly by the software program. Each group played 120 games in total. Participants were not told how many games they would play. They were paid at the end of the experiment based on the time it took the group to complete an average round and the number of mistakes that were made. The nature of the task and rewards were explained to the participants before they began playing. (See the technical supplement for details of the procedure.)

At the conclusion of all games, participants were asked to record their labels for each image used in the study. Then, they were asked to record some demographic information and whether they were familiar with the other persons in the group. Finally, they were informed of the performance of the group in time and accuracy and paid equally according to group performance.

The experiments were conducted in three phases. $13 \mathrm{C}$ and $14 \mathrm{~T}$ groups were run in Study 1. It was noticed during these experiments that some bystanders were able to hear their group members despite the use of soundproofed headsets, depending on how loud the sender and receiver spoke. We therefore revised the software so that a continuous recording of pouring rain was played over the headset of the bystander in the private communication condition. Study 2 had 73 groups (21 private $\mathrm{C}, 18 \mathrm{C}$ with transparent communication, $16 \mathrm{~T}$ private, $18 \mathrm{~T}$ with transparent communication). In Study 3, amendments were made to the software so that each participant could see who was playing which role in each game. Participants in Study 3 were also told at the beginning of the experiment whether they would be playing in a $\mathrm{T}$ or $\mathrm{C}$ structure. We call this the 'transparent structure' condition. $10 \mathrm{C}$ and $13 \mathrm{~T}$ groups (all with private communication) were run in Study 3.

\section{Results}

We start with a visual examination of the differences in triads' performance across $\mathrm{T}$ and $\mathrm{C}$ groups in the different treatments. Fractional-polynomial prediction plots drawn on Stata (Statacorp, 2015) depict group means and confidence intervals around the means. T-tests convey statistical significance of differences. (We use Studies 2 and 3 in Figures 2-4 and associated t-tests in order to 
clearly distinguish transparent and private communication groups. Other analyses pool data from all studies.)

Our baseline treatment is based on private communication - the bystanders were clearly prevented from hearing the interacting dyad. When considering the entire span of the experiment, transitive groups engaged in private communication make more mistakes $(\operatorname{Pr}(\mathrm{T}>\mathrm{t})=$ $0.051)$ but do not on average take longer per round $(\operatorname{Pr}(T<t)=0.262)$. Figure 2 shows clearly that transitive groups start with a disadvantage but eventually catch up to cyclical groups. Thus, transitive groups experience a transient disadvantage over cyclical ones.

Figure 2. Private communication (Study 2: $21 \mathrm{C}, 16 \mathrm{~T}$ groups)

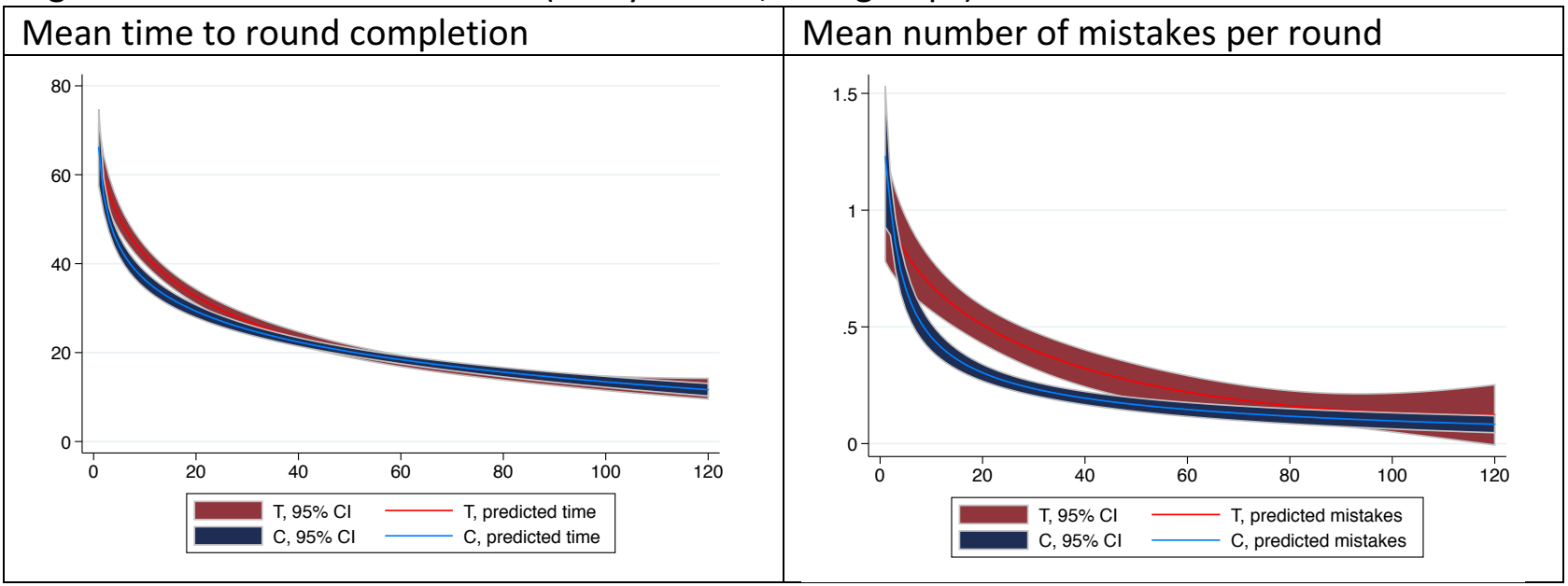

We next examine transparent communication, where the bystander can hear the message sender and receiver, and can see the message receiver's choices. As expected, transparent communication leads to an improvement in speed (17 versus 22 seconds on average per round $(\operatorname{Pr}(\mathrm{T}>\mathrm{t})=0.000)$ and accuracy $(.19$ versus .25 mistakes per round $\operatorname{Pr}(\mathrm{T}>\mathrm{t})=0.077))$ relative to the private communication condition. Further t-tests indicate that transparent communication helps both $\mathrm{T}$ and $\mathrm{C}$ groups progress through rounds quicker (18 vs 22 seconds, $\operatorname{Pr}(\mathrm{T}>\mathrm{t})=0.009$ and 16 vs 21 seconds, $\operatorname{Pr}(\mathrm{T}>\mathrm{t})=0.000$ respectively). The improvement in accuracy with transparent compared to private communication is limited to T groups, however (.19 versus .30 mistakes per round $(\operatorname{Pr}(T>t)=0.043)$ in $T$ groups and .20 versus .21 mistakes per round $(\operatorname{Pr}(T>t)=0.404)$ in $C$ groups).

Figure 3. Transparent communication (Study 2: $18 \mathrm{C}, 18 \mathrm{~T}$ groups)

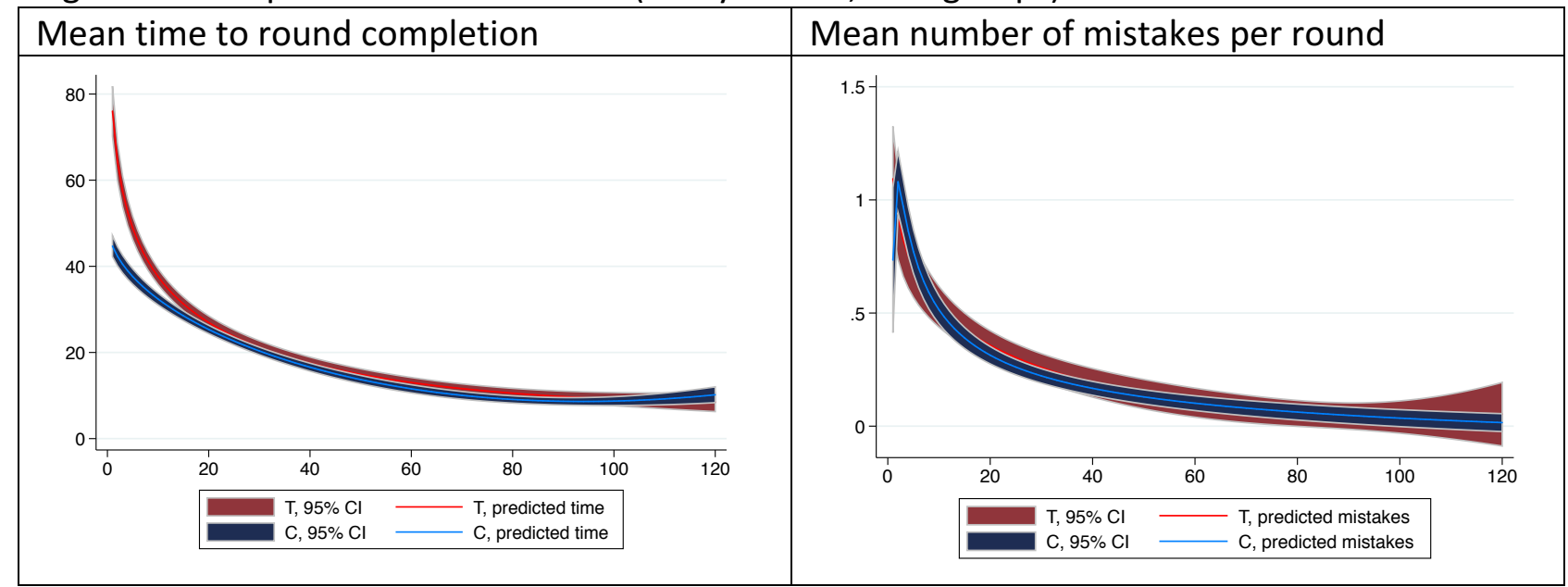


Figure 3 shows that there is no difference in mistakes between $\mathrm{T}$ and $\mathrm{C}$ groups in the transparent communication groups, unlike in the private groups $(\operatorname{Pr}(T<t)=0.568)$. There is a big difference in round completion times at the very beginning, which quickly disappears and does not show up in the entire span of the experiment $(\operatorname{Pr}(\mathrm{T}<\mathrm{t})=0.098)$. It seems that participants in $\mathrm{T}$ groups understand there are conflicting codes early in the experiment when communication is transparent, take longer to complete rounds and establish common codes, and reflect this learning in round completion times later on.

Figure 4. Transparent structure (Study 3: $10 \mathrm{C}, 13 \mathrm{~T}$ groups)

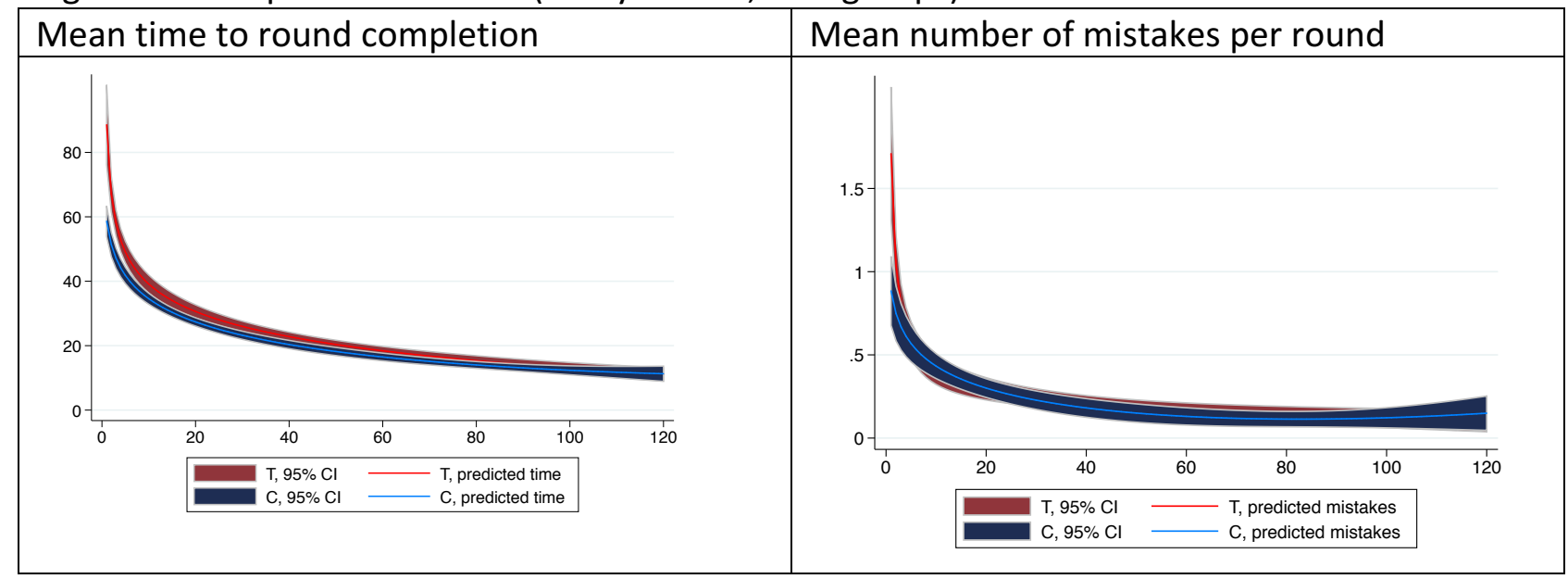

Figure 4 shows performance in the transparent structure treatment, where participants knew of the triadic structure beforehand and were informed of who they were interacting with in each round. While transparent structure seems to reduce differences across $\mathrm{T}$ and $\mathrm{C}$ groups in mistakes, the curves in the transparent treatment are statistically undistinguishable from the baseline ones. Private communication groups have statistically identical performance on time and accuracy, regardless of whether the structure was transparent to them or not. When broken down by structure, however, we find $C$ groups to be faster ( 20 versus 22 seconds on average, $\operatorname{Pr}(T>t)=$ $0.049)$, and no more accurate $(\operatorname{Pr}(T>t)=0.3639)$. Visual inspection of Figures $2-4$ also show transparent structure groups to behave more similarly to the transparent communication groups than to other private communication groups.

Finally, Figure 5 shows the combined studies (1-3), broken down by familiarity of participants. Groups consisting of strangers make more mistakes in T groups at the very beginning, equalize their mistakes in the two conditions at the cost of increasing time in T groups, and achieve equality of $\mathrm{T}$ and $\mathrm{C}$ outcomes after the $60^{\text {th }}$ round, by which time each dyad will have interacted 20 times on average. Groups of friends show a very different pattern. They also experience greater difficulties in achieving early coordination in T groups relative to $C$ groups, as evidenced in the difference in mistakes. $C$ groups make more mistakes at the very start but quickly improve their accuracy. $T$ groups continue to make more mistakes than $C$ groups until round 40 . $T$ and $C$ groups do not vary in round completion times, however. Transitive groups of strangers take longer per round than cyclical groups of strangers ( 25 versus 19 seconds, $\operatorname{Pr}(T>t)=0.023$ ). So do mixed groups (22 versus 20 seconds, $\operatorname{Pr}(T>t)=0.052$ ). But not groups of friends $(\operatorname{Pr}(T>t)=0.779)$. Neither group shows a difference in accuracy between $T$ and $C$. Moreover, transitive groups of friends are faster than transitive groups of strangers (18 versus 25 seconds, $\operatorname{Pr}(T>t)=0.000$ ) and 
transitive mixed groups (18 versus 22 seconds, $\operatorname{Pr}(T>t)=0.020$ ), but familiarity provides no advantage in $\mathrm{C}$ groups.

Figure 5. Three levels of familiarity (all studies pooled: 17 strangers, 67 mixed, 39 friends)

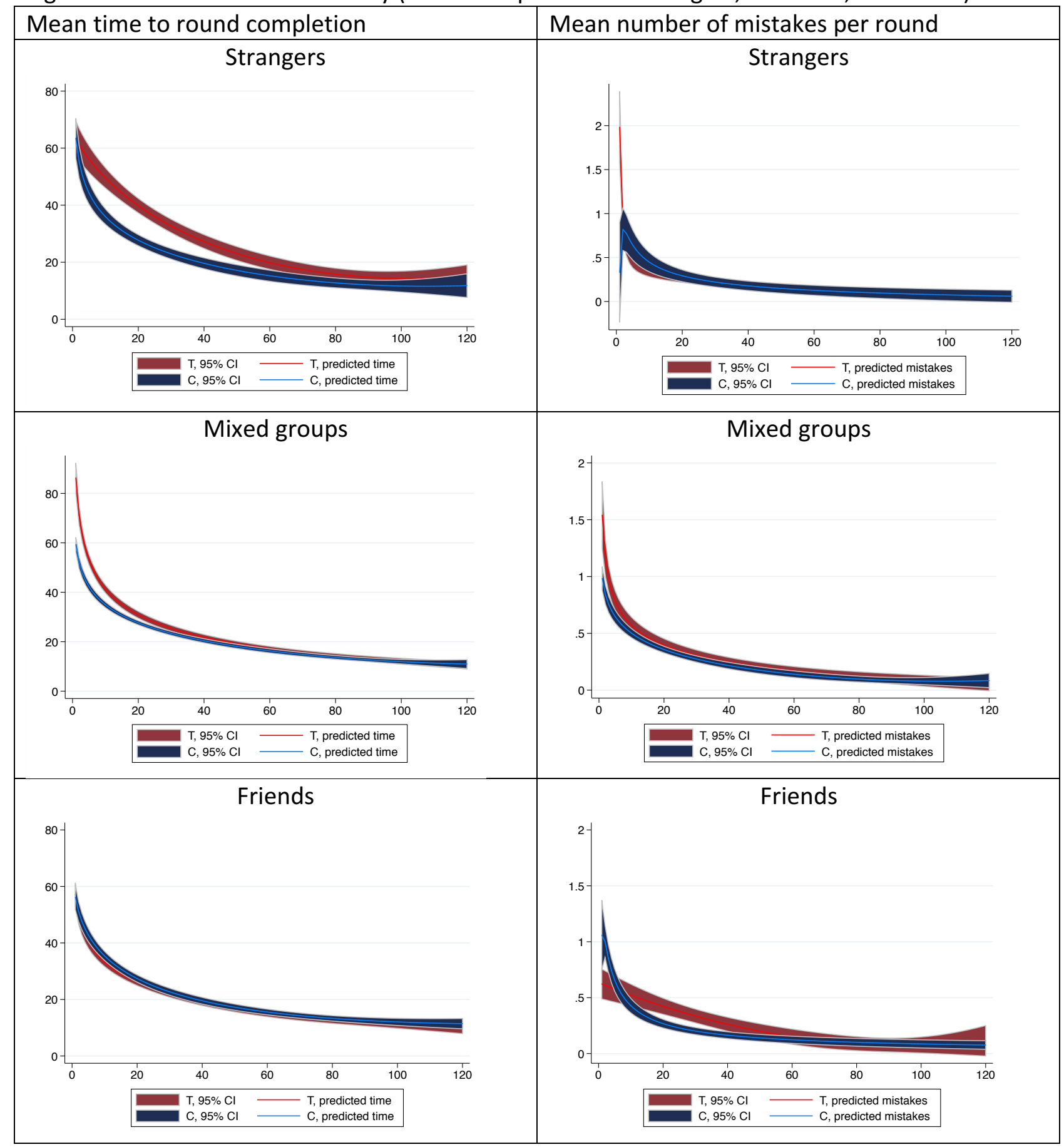

In summary, code coordination in transitive structures is more difficult to achieve, especially when subjects are strangers. The question arising is thus: why is common ground harder to create in such cases? As suggested above, common ground has different aspects. One is lexical - shared assumptions about how the lexicon refers to entities in the world. Another one is "positional": there is a shared understanding about the position and role of each communicating agent. A third aspect is the behavioral one: what "rules of conversation" hold? How to behave in an interaction? 
Findings for different conditions in the experiment point towards behavioral common ground accounting for the difference in T and C groups. As the "transparent structure" treatment seems indistinguishable from the baseline, the hypothesis that "positional" common ground matters can be ruled out. The differences in performance arising from variation in familiarity are most likely due to behavioral common ground. It is highly implausible that friends already have a common lexicon for the figure they observe in the experiment - and groups of friends do no better than other groups at the start of the experiment. The transparent communication treatment facilitates both the creation of lexical common ground and the development of common "behavioral" ground, as bystanders can observe both what lexicon others agree upon and how they interact. Indeed, groups of friends do not benefit from transparent communication to the same extent that other groups do (16 versus 19 seconds to complete private versus transparent communication rounds in Study 2 for friends $(\operatorname{Pr}(T>t)=0.060)$, compared to 17 versus 23 seconds for non-friends $(\operatorname{Pr}(T>t)=0.000))$. Data thus suggests that differences in the creation of behavioral common ground play an important role in explaining why $T$ triads are harder to coordinate.

Table 1. Random intercept mixed model regressions predicting time to complete rounds (In)

\begin{tabular}{|c|c|c|c|c|}
\hline & $\begin{array}{l}(1) \\
\text { All } \\
\end{array}$ & $\begin{array}{c}(2) \\
\text { Private }\end{array}$ & $\begin{array}{l}(3) \\
\text { All }\end{array}$ & $\begin{array}{c}(4) \\
\text { Private }\end{array}$ \\
\hline Friends & $\begin{array}{c}-0.170^{*} \\
(0.057)\end{array}$ & $\begin{array}{c}-0.185^{*} \\
(0.055)\end{array}$ & $\begin{array}{c}-0.386^{*} \\
(0.090)\end{array}$ & $\begin{array}{c}-0.507^{*} \\
(0.103)\end{array}$ \\
\hline 030C & $\begin{array}{c}-0.097^{*} \\
(0.045)\end{array}$ & $\begin{array}{c}-0.077^{*} \\
(0.043)\end{array}$ & $\begin{array}{c}-0.239 * \\
(0.071)\end{array}$ & $\begin{array}{c}-0.207^{*} \\
(0.080)\end{array}$ \\
\hline Friends X 030C & $\begin{array}{l}0.162^{*} \\
(0.080)\end{array}$ & $\begin{array}{c}0.114 \\
(0.075)\end{array}$ & $\begin{array}{l}0.313^{*} \\
(0.126)\end{array}$ & $\begin{array}{c}0.409^{*} \\
(0.139)\end{array}$ \\
\hline Group's prior experience with same target $(\ln )$ & $\begin{array}{c}-0.312^{*} \\
(0.010)\end{array}$ & $\begin{array}{c}-0.299^{*} \\
(0.012)\end{array}$ & $\begin{array}{c}-0.319^{*} \\
(0.017)\end{array}$ & $\begin{array}{c}-0.306^{*} \\
(0.020)\end{array}$ \\
\hline Friends X Group's prior exp. with target (ln) & & & $\begin{array}{c}-0.021 \\
(0.031)\end{array}$ & $\begin{array}{c}-0.051 \\
(0.039)\end{array}$ \\
\hline 030C X Group's prior exp. with target (ln) & & & $\begin{array}{c}0.033 \\
(0.024)\end{array}$ & $\begin{array}{c}0.067^{*} \\
(0.030)\end{array}$ \\
\hline Friends X 030C X Prior exp. with target (ln) & & & $\begin{array}{c}-0.021 \\
(0.042)\end{array}$ & $\begin{array}{c}-0.050 \\
(0.052)\end{array}$ \\
\hline Group's experience with other targets $(\ln )$ & $\begin{array}{c}-0.251^{*} \\
(0.008)\end{array}$ & $\begin{array}{c}-0.239^{*} \\
(0.010)\end{array}$ & $\begin{array}{c}-0.279^{*} \\
(0.014)\end{array}$ & $\begin{array}{c}-0.268^{*} \\
(0.017)\end{array}$ \\
\hline Friends X Group's exp. with other targets (ln) & & & $\begin{array}{l}0.064^{*} \\
(0.025)\end{array}$ & $\begin{array}{l}0.103^{*} \\
(0.032)\end{array}$ \\
\hline 030C X Group's exp. with other targets (ln) & & & $\begin{array}{c}0.026 \\
(0.020)\end{array}$ & $\begin{array}{c}0.010 \\
(0.024)\end{array}$ \\
\hline Friends X 030C X Prior exp. with other targets (ln) & & & $\begin{array}{c}-0.032 \\
(0.035)\end{array}$ & $\begin{array}{c}-0.060 \\
(0.043)\end{array}$ \\
\hline Constant & $\begin{array}{l}4.135^{*} \\
(0.039)\end{array}$ & $\begin{array}{l}4.160^{*} \\
(0.040)\end{array}$ & $\begin{array}{l}4.250^{*} \\
(0.050)\end{array}$ & $\begin{array}{c}4.275^{*} \\
(0.054)\end{array}$ \\
\hline Random effects parameters: & & & & \\
\hline $\operatorname{Var}($ cons $)$ & $\begin{array}{c}0.040 \\
(0.005)\end{array}$ & $\begin{array}{c}0.024 \\
(0.004)\end{array}$ & $\begin{array}{c}0.040 \\
(0.005)\end{array}$ & $\begin{array}{c}0.024 \\
(0.004)\end{array}$ \\
\hline Var (residual) & $\begin{array}{c}0.302 \\
(0.004) \\
\end{array}$ & $\begin{array}{c}0.319 \\
(0.004)\end{array}$ & $\begin{array}{c}0.301 \\
(0.004)\end{array}$ & $\begin{array}{c}0.318 \\
(0.004) \\
\end{array}$ \\
\hline Observations & 14,653 & 10,419 & 14,653 & 10,419 \\
\hline Number of groups & 123 & 87 & 123 & 87 \\
\hline Wald chi2 & 8211.21 & 5088.12 & 8248.56 & 5133.43 \\
\hline LR test vs linear model & 1462.82 & 529.96 & 1462.80 & 531.23 \\
\hline
\end{tabular}


We find further evidence for these conjectures in an examination of how groups perform throughout the experiment. In Table 1, we present estimates from regression models of the time it takes subjects to complete each round of matching. We see that groups where all three participants were familiar with each other before the experiment finish rounds in less time on average than other groups. Cyclical groups also are advantaged on average, compared to transitive groups. The interaction of the two variables is positive, indicating that the disadvantage of transitivity does not affect groups of friends as much.

Table 1 also shows the effects of learning from experience. We estimate the learning effect from triad's prior experience by including a count of prior rounds. We separate these into rounds where the triad described the same target as in the focal round and rounds where a different target was described. Both experiences are likely to build both lexical and behavioral common ground. (Learning from other images may build lexical common ground through a differentiation effect as participants learn to distinguish images from others). Though, behavioral common ground is more likely to be the main source of learning in experience with other targets. Model 1 shows that both experiences contribute to learning. Model 2 excludes experimental sessions with transparent communication and finds the same pattern of results.

Models 3 and 4 interact prior experience variables with structure (cyclicality) and familiarity. We find that cyclical groups learn less from prior experience with the same target compared to transitive groups under conditions of private communication. There is no effect of structure on learning from experience in transparent communication groups. Furthermore, groups of friends learn less from prior experience with other targets. In other words, transitive groups and groups lacking prior familiarity with each other learn more throughout the experiment, and eventually catch up with cyclical groups and groups of friends. Transitive groups catch up through building target-specific common ground, while strangers catch up through learning from non-targetspecific experience, possibly building behavioral common ground through those experiences.

Table 2 repeats the same analysis for mistakes groups make in each round. Models 3 and 4 show that as with time, groups of friends learn less from prior experience with other targets. In these models, it is also evident that they learn more from prior experience with the same target. This is because friends make just as many mistakes as non-friends on average, and in fact make more mistakes at the very start of the experiment. Having started with more mistakes than non-friends, they catch up faster by learning from prior experience (and mistakes).

We next examine whether structure and familiarity have lasting effects on codes. To what extent do coordination difficulties translate into the kind of code that is developed? Christie, Luce, and Macy (1952) found that noise in communication leads to development of redundant codes as actors develop synonyms in clarifying misunderstandings. Even as groups eventually develop a common code and do not need to use synonyms to communicate, the semantic redundancy is retained in memory. We examine whether the lack of fluency in T groups may have caused the same kind of redundancy to arise in our experiments by examining the codes elicited at the end of the experiment in private communication groups (16 target images for each of the groups), across $\mathrm{T}$ and $\mathrm{C}$ groups made up of friends, strangers, and mixed dyads.

We find that groups of strangers have different codes across $T$ and $C$ groups while groups of friends and mixed groups show no statistically significant difference across structures. Strangers are more likely than other groups to develop redundant codes, i.e. instances where multiple codes 
exist either at the group or dyad level, whether in $T$ structures $(\operatorname{Pr}(T<t)=0.071)$ or in $C$ structures $(\operatorname{Pr}(\mathrm{T}>\mathrm{t})=0.017)$. This is consistent with our conjecture that lack of behavioral common ground creates coordination difficulties that lead to an accumulation of multiple codes as solutions.

Table 2. Random intercept mixed model regressions predicting number of mistakes in each round

\begin{tabular}{|c|c|c|c|c|}
\hline & $\begin{array}{l}(1) \\
\text { All }\end{array}$ & $\begin{array}{c}(2) \\
\text { Private }\end{array}$ & $\begin{array}{l}\text { (3) } \\
\text { All }\end{array}$ & $\begin{array}{c}(4) \\
\text { Private }\end{array}$ \\
\hline Friends & $\begin{array}{c}-0.093 \\
(0.197)\end{array}$ & $\begin{array}{c}-0.013 \\
(0.228)\end{array}$ & $\begin{array}{c}-0.836^{*} \\
(0.380)\end{array}$ & $\begin{array}{c}-0.964^{*} \\
(0.446)\end{array}$ \\
\hline $030 \mathrm{C}$ & $\begin{array}{l}-0.061 \\
(0.155)\end{array}$ & $\begin{array}{c}-0.004 \\
(0.177)\end{array}$ & $\begin{array}{l}-0.112 \\
(0.285)\end{array}$ & $\begin{array}{l}-0.026 \\
(0.330)\end{array}$ \\
\hline Friends X 030C & $\begin{array}{l}-0.028 \\
(0.277)\end{array}$ & $\begin{array}{l}-0.305 \\
(0.310)\end{array}$ & $\begin{array}{c}0.578 \\
(0.521)\end{array}$ & $\begin{array}{c}0.337 \\
(0.597)\end{array}$ \\
\hline Group's prior experience with same target (ln) & $\begin{array}{l}-0.614^{*} \\
(0.054)\end{array}$ & $\begin{array}{l}-0.561^{*} \\
(0.062)\end{array}$ & $\begin{array}{c}-0.582^{*} \\
(0.092)\end{array}$ & $\begin{array}{l}-0.550^{*} \\
(0.103)\end{array}$ \\
\hline Friends X Group's prior exp. with target (ln) & & & $\begin{array}{c}-0.526^{*} \\
(0.173)\end{array}$ & $\begin{array}{l}-0.505^{*} \\
(0.200)\end{array}$ \\
\hline 030C X Group's prior exp. with target (ln) & & & $\begin{array}{c}0.105 \\
(0.131)\end{array}$ & $\begin{array}{c}0.170 \\
(0.150)\end{array}$ \\
\hline Friends X 030C X Prior exp. with target (ln) & & & $\begin{array}{l}0.470^{*} \\
(0.238)\end{array}$ & $\begin{array}{c}0.352 \\
(0.270)\end{array}$ \\
\hline Group's experience with other targets (ln) & $\begin{array}{c}-0.383^{*} \\
(0.039)\end{array}$ & $\begin{array}{l}-0.335^{*} \\
(0.045)\end{array}$ & $\begin{array}{c}-0.434^{*} \\
(0.066)\end{array}$ & $\begin{array}{l}-0.390^{*} \\
(0.075)\end{array}$ \\
\hline Friends X Group's exp. with other targets (ln) & & & $\begin{array}{l}0.367^{*} \\
(0.127)\end{array}$ & $\begin{array}{l}0.420^{*} \\
(0.147)\end{array}$ \\
\hline 030C X Group's exp. with other targets (ln) & & & $\begin{array}{l}-0.017 \\
(0.094)\end{array}$ & $\begin{array}{l}-0.047 \\
(0.109)\end{array}$ \\
\hline Friends X 030C X Prior exp. with other targets (ln) & & & $\begin{array}{l}-0.309 \\
(0.173)\end{array}$ & $\begin{array}{l}-0.283 \\
(0.197)\end{array}$ \\
\hline Constant & $\begin{array}{l}0.338^{*} \\
(0.148)\end{array}$ & $\begin{array}{l}0.369^{*} \\
(0.073) \\
\end{array}$ & $\begin{array}{l}0.477^{*} \\
(0.199)\end{array}$ & $\begin{array}{c}0.391 \\
(0.224)\end{array}$ \\
\hline Random effects parameters: & & & & \\
\hline ln alpha & $\begin{array}{c}1.14 \\
(0.050)\end{array}$ & $\begin{array}{c}1.13 \\
(0.058)\end{array}$ & $\begin{array}{c}1.13 \\
(0.051)\end{array}$ & $\begin{array}{c}1.12 \\
(0.058)\end{array}$ \\
\hline $\operatorname{Var}($ cons $)$ & $\begin{array}{c}0.417 \\
(0.068)\end{array}$ & $\begin{array}{c}0.369 \\
(0.073)\end{array}$ & $\begin{array}{c}0.419 \\
(0.069)\end{array}$ & $\begin{array}{c}0.372 \\
(0.073)\end{array}$ \\
\hline Observations & 14,653 & 10,419 & 14,653 & 10,419 \\
\hline Number of groups & 123 & 87 & 123 & 87 \\
\hline Wald chi2 & 871.19 & 541.93 & 884.56 & 553.39 \\
\hline LR test vs linear model & 362.50 & 235.01 & 364.87 & 238.90 \\
\hline
\end{tabular}

In consonance with their coordination performance, T groups of strangers, who presumably experienced the greatest difficulty of coordination due to structure and lack of prior familiarity, are more likely than $C$ groups of strangers to have redundant codes $(\operatorname{Pr}(T<t)=0.006)$. T groups of strangers have more redundant codes even when they only report group-level codes $(\operatorname{Pr}(T<t)=$ 0.040).

Additional evidence comes from measurement of the length of codes reported by participants. Participants in T groups of strangers on average report codes of 84 characters as opposed to the 40 characters in $C$ groups of strangers $(\operatorname{Pr}(T<t)=0.000)$. The difference in code length is visible 
even in instances where only group level codes are reported: 70 versus 29 characters $(\operatorname{Pr}(\mathrm{T}<\mathrm{t})=$ 0.000). This difference arises as descriptions of multiple features are retained as codes, similar to multiple labels being retained.

Figure 6. Codes reported at the end of experiments for targets in private communication groups

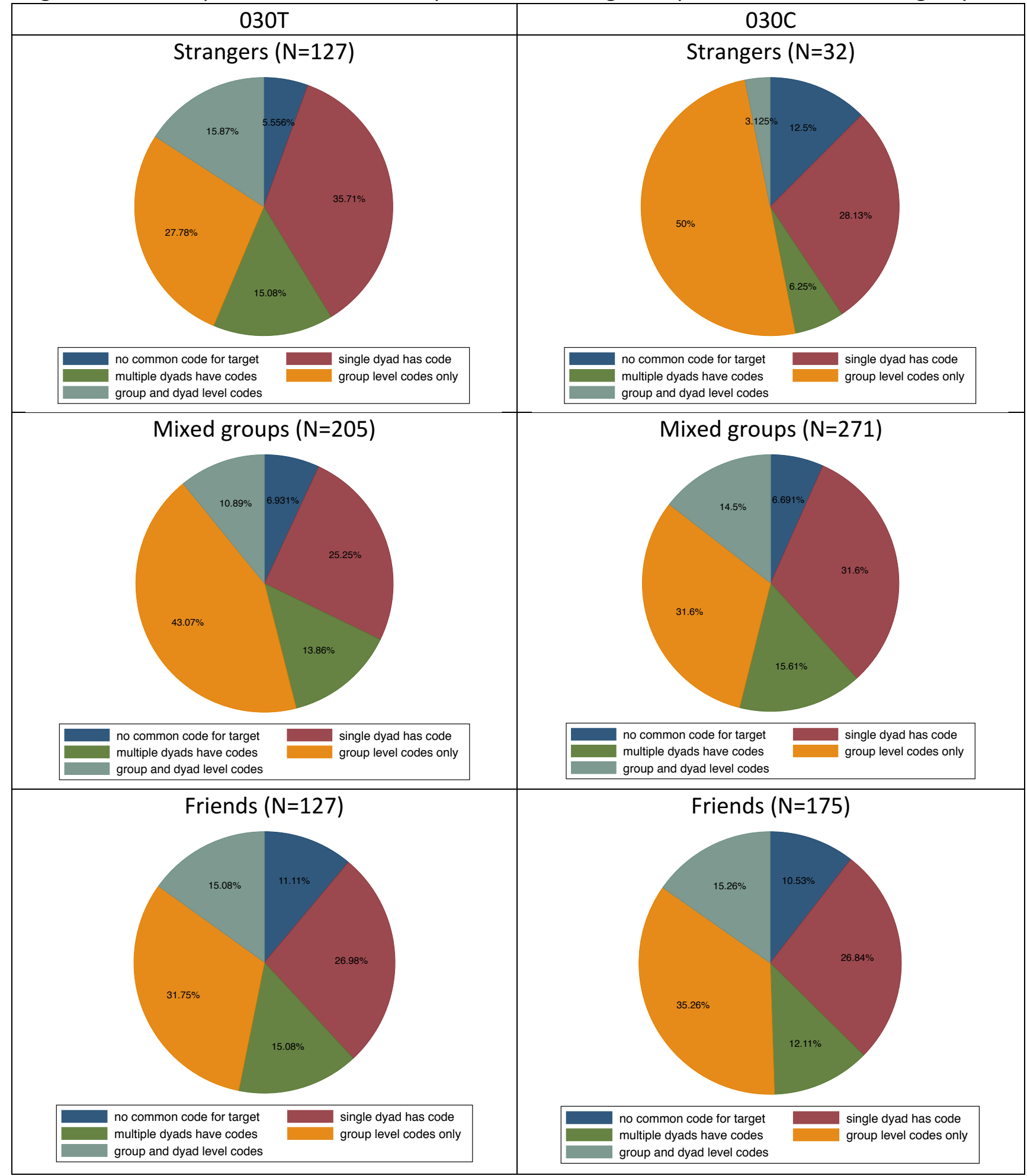

We also find differences in code specialization. Figure 6 depicts a classification of codes as 'group level codes only' where all three participants in a group reported the same label(s) for the same 
image, 'group and dyad level codes' where at least one dyad reported a label that was not shared by the third person in the group in addition to all three participants reporting a common label, 'single dyad has code' where only one dyad reported the same label(s) that the third person did not share, 'multiple dyads have codes' where dyad specific labels that point to multilingualism were reported across the group, and 'no common code for target' where all three participants gave different labels for the same image.

Among groups of strangers, members of $\mathrm{T}$ groups are as likely as members of $\mathrm{C}$ groups to have developed some group level code $(\operatorname{Pr}(\mathrm{T}>\mathrm{t})=0.161)$. However, transitive groups of strangers are less likely than cyclical groups of strangers to report only group codes $(\operatorname{Pr}(T>t)=0.007)$, more likely to report only dyadic codes (whether a single dyadic code or multiple dyadic codes) $\operatorname{Pr}(T<t)$ $=0.053)$, and more likely to report dyadic codes in combination with group level codes $(\operatorname{Pr}(\operatorname{T}>\mathrm{t})=$ 0.030).

Among all transitive groups, groups of strangers are less likely to report only group level codes $(\operatorname{Pr}(\mathrm{T}>\mathrm{t})=0.016)$, or to have developed any group level code at all $(\operatorname{Pr}(\mathrm{T}>\mathrm{t})=0.073)$. However, among all cyclical groups, strangers are no less likely to have developed some group level code $(\operatorname{Pr}(\mathrm{T}>\mathrm{t})=0.745)$ and even more likely than other groups to report only group level codes $(\operatorname{Pr}(\mathrm{T}<$ $\mathrm{t})=0.023)$.

Table 3. Cross-classified mixed models estimating time to round completion for each target in private rounds

(1) (2) (3) (4)

Mean for All Mean for All Last Round Last Round

\begin{tabular}{lcccc} 
Group level code exists & $-3.153^{*}$ & & $-1.818^{*}$ & \\
& $(0.709)$ & & $(0.784)$ & $-1.711^{*}$ \\
Group level code only & & $-3.278^{*}$ & & $(0.865)$ \\
& & $(0.782)$ & & -2.081 \\
Dyad and group level code & & $-2.845^{*}$ & & $(1.198)$ \\
& & $(1.083)$ & & $0.067^{*}$ \\
Length of label & $0.069^{*}$ & $0.069^{*}$ & $0.066^{*}$ & $(0.011)$ \\
& $(0.011)$ & $(0.011)$ & $(0.010)$ & $9.199^{*}$ \\
Constant & $18.760^{*}$ & $18.802^{*}$ & $9.238^{*}$ & $(1.121)$ \\
& $(1.410)$ & $(1.415)$ & $(1.112)$ & \\
Random effects parameters: & & & & 4.513 \\
Var (group) & 7.816 & 7.794 & 4.468 & $(2.509)$ \\
& $(2.764)$ & $(2.760)$ & $(2.496)$ & 4.709 \\
Var (target) & 16.632 & 16.641 & 4.683 & $(2.525)$ \\
& $(6.557)$ & $(6.560)$ & $(2.514)$ & $(6.487$ \\
Var (residual) & 104.476 & 104.468 & 131.538 & 921 \\
& $(5.079)$ & $(5.078)$ & $(6.398)$ & 58 \\
\hline Observations & 921 & 921 & 921 & 16 \\
Number of groups & 58 & 58 & 58 & 48.08 \\
Number of targets & 16 & 16 & 16 & 18.56 \\
Wald chi2 & 68.72 & 68.88 & 2569.52 & 18.49 \\
LR test vs linear model & 108.39 & 108.33 & & \\
\hline
\end{tabular}

standard errors in parentheses

${ }^{*} \mathrm{p}<0.05$ 
We examine the impact of these resulting codes by examining the effect of type of code on coordination outcomes. Analyses reported in Table 3 show that groups that report at least one group level code at the end of the experiment finish the round faster, both throughout the experiment (Models 1 and 2) and in the last round that the target image appears (Models 3 and 4). Models 2 and 4 look at greater detail by separating groups that only report group level codes from groups that report both group level and dyadic codes. Only group level codes improve coordination in the last round a target appears. This confirms that the differences we see across groups of different structure and familiarity in the existence of group level codes has a lasting effect on coordination. Table 3 also shows that length of labels used (averaged across all three participants) has an independent positive effect on round completion times, documenting the predictable inefficiencies of long labels.

\section{Discussion}

Organizational economics illuminates the inherent tradeoffs associated with code specialization, the sociological perspective invites to look at the relational context of code creation, and psycholinguistics provides the tools for studying the process of creating common codes in groups. This study shows that social structure affects both the process and the outcome of creation of shared codes in triadic groups. We compared a transitive structure and a cyclical one. Transitive structure makes it harder to reach a common code, and generate less efficient codes than the cyclical one. This may be at first sight surprising, as the former structure is more common than the latter, and it provides some hierarchical control over the process of code generation that might ensure superior coordination. A closer analysis of our experimental treatments suggests that the coordination difficulties in transitive triads may be explained by the difficulty to establish a "behavioral common ground "due to the asymmetry of such structure. The fact that such problems arise only in triads of strangers reinforces the hypothesis that coordination in the transitive structure may suffer from a deficit of "social fluency" in participants, that requires a longer process of acquisition of a common understanding of the differentiated behavior which is expected from each of them in interaction. They need to learn how their actions and others' actions contingent on their own actions are appropriate.

It is possible that the methods by which people achieve common understanding vary across different structures. Unfortunately, we are unable to undertake a study of potential variation in this study as we have not recorded the conversations between participants in the experiment. Future work may use conversation analysis to examine whether the difference in $\mathrm{T}$ and $\mathrm{C}$ structures gives rise to differences in the interactions leading to mutual understanding (Garfinkel 1986, Sacks 1992).

The experiment shows that, if given enough time, participants do develop such behavioral common ground even within transitive structures. But even the transient mis-coordination matters for organizational coordination. Because the code is a cumulation of past solutions to coordination problems, the less fluent the interaction, the less efficient is the resulting code.

An important result of our experiment is that within a triad a multiplicity of co-existing codes may arise. While this is an outcome predicted by economic models of organizational codes, the reasons that make it happen in our experiment are not directly related to the advantages of specialization. Instead, our results seem to provide evidence of the Simmelian argument that triads may 
disintegrate into three parties of two persons each. We show that the way in which dyads are configured into a triad affect the likelihood of this happening and suggest that the difficulties of creating a behavioral common ground may account for such an outcome.

\section{References}

Brennan, S. E., \& Clark, H. H. 1996. Conceptual pacts and lexical choice in conversation. Journal of Experimental Psychology: Learning, Memory, and Cognition, 22(6), 1482.

Bunderson, J. S., Van Der Vegt, G. S., Cantimur, Y., \& Rink, F. 2016. Different views of hierarchy and why they matter: hierarchy as inequality or as cascading influence. Academy of Management Journal, 59(4), 1265-1289.

Christie, L. S., Luce, R. D., \& Macy, J. 1952. Communication and learning in task-oriented groups. Technical Report No 231, Research Laboratory of Electronics, MIT: Cambridge, UK.

Clark, H. H. 1996. Using language. 1996. Cambridge University Press: Cambridge, UK.

Clark, H. H., \& Schaefer, E. F. 1989. "Contributing to discourse”. Cognitive science, 13(2), 259-294.

Clark, H. H., \& Wilkes-Gibbs, D. 1986. "Referring as a Collaborative Process". Cognition, 22: 1-39.

Fay, N., Garrod, S., Roberts, L., Swoboda, N. 2010. "The Interactive Evolution of Human Communication Systems", Cognitive Science, 34(3), 351-386.

Galantucci, B., Theisen, C., Gutierrez, E. D., Kroos, C., Rhodes, T. 2012. "The Diffusion of Novel Signs Beyond the Dyad", Language Sciences, 34(5), 583-590.

Granovetter, M. (1985). Economic action and social structure: The problem of embeddedness. American journal of sociology, 91(3), 481-510.

Holland, P., \& Leinhardt, S. 1970. A Method for Detecting Structure in Sociometric Data. American Journal of Sociology, 76(3): 492-513.

Krauss, R. M., \& Glucksberg, S. (1977). Social and nonsocial speech. Scientific American, 236(2), 100-105.

Leifer, E. M. (1991). Actors and observers: a theory of skill in social relationships. Garland.

Ludlow, P. 2014. Living words: Meaning underdetermination and the dynamic lexicon. Oxford University Press: Oxford, UK.

Sacks, H. (1992). "Lectures on Conversation, Volumes I and II" Edited by G. Jefferson with Introduction by E.A. Schegloff, Blackwell, Oxford.

Simmel, G. (1950). The Sociology of Georg Simmel. The Free Press: Glencoe, IL. 
Tushman, M. L., \& Katz, R. 1980. External communication and project performance: An investigation into the role of gatekeepers. Management science, 26(11), 1071-1085.

Weber, R. A., Camerer, C. F. 2003. "Cultural Conflict and Merger Failure: An Experimental Approach", Management Science, 49(4), 400-415.

Wernerfelt, B. 2004. Organizational languages. Journal of Economics \& Management Strategy, 13(3), 461-472.

Wilkes-Gibbs, D., \& Clark, H. H. (1992). Coordinating beliefs in conversation. Journal of memory and language, 31(2), 183-194.

\section{Technical Supplement}

\section{Procedure}

Participants were brought into the lab in groups of three and seated randomly at terminals separated by partitions. After being instructed on the use of gaming headsets, they were directed to turn their attention to their individual screens. Participants first saw a consent form. Upon giving their consent, they were shown a video describing the experimental game. The video explained the three roles they could be asked to play in each round of the game - message sender, message receiver, and bystander - and presented sample screens associated with each role (Figures 1-3). It also informed subjects that their payment would be contingent on the group's overall performance and determined by the duration of the rounds and the number of mistakes made during the game. Participants were presented with two questions testing their understanding of the roles and payment conditions after the video. Those that made a mistake on the questions were shown the video again. Others waited until everyone was ready to proceed to the experiment.

The first screen contained the set of 16 tangram images used in the experiment. Participants were asked to describe each image in turn, pretending they were the speaker in the experiment, and their voices were recorded by their terminals.

The matching game started after all participants finished describing the tangrams. (In Studies 2 and 3, participants who finished describing the tangrams heard a recording of rainfall while they waited for the others in the group to finish their descriptions.)

Each group played 120 rounds in the matching game. Role assignments -indicating which dyad would actively communicate- and the target image to be described for each round were randomly determined at the start of the game by the software program. While role assignments were randomly determined, role distributions throughout the game depended on the experimental configuration (030C and 030T) to which the game was randomly assigned. 030T groups played the game in dyads ij-ik-jk in random order, while 030C groups played the game in dyads ij-jk-ki in random order. The target image for each round was also randomly determined.

In each round, the participant assigned to the role of the 'message sender' tried to accurately describe the target image for that round to the participant assigned to the role of the 'message 
receiver'. The message receiver tried to correctly identify the target image and select it on her screen. Participants' screens varied with respect to the order in which the 16 tangrams were placed on the screen so that they could not give each other coordinates for the target images (Figures S1-S3 do not reflect this because they show the sample screens shown to the participants in the instructional video). Each participant saw the tangrams in the same location in each round, however, so there would be no confusion arising from target placement.

Participants in the 'transparent structure' condition (Study 3) were also shown an indication of the focal dyad in each round on their screens.

Participants' speakers and microphones were controlled by the experimental software so that only the message sender and receiver could speak during a round. Bystanders in the 'transparent communication' condition could hear their communication but could not speak. Bystanders in the private communication conditions heard a recording of rainfall in Studies 2 and 3.

The receiver was able to make more than one selection and the dyadic interaction continued until the receiver selected the correct image on the screen. Once the correct selection was made, the experiment progressed to the next round. The experimental software recorded all selections of the receiver (providing the mistake count in the round) and the time spent until correct selection. We present transcripts of several rounds of two different experimental sessions where subjects describe the same image in Tables S1 and S2.

After the subjects played 120 rounds as a triad, they saw the description screen once more and were asked to describe each image again. Their verbal descriptions were recorded as before.

Next, participants responded to questions to indicate their age, their gender, and how many of the other two participants they knew.

In the next screen, each participant received information about the group's total number of mistakes, the average round time in the game, and the payment per person.

Finally, participants progressed to a debrief screen. After the subjects read the debrief screen and entered any comments they had, the administrator made the payment in cash, thanked the participants and concluded the experiment.

\section{$\underline{\text { Participants }}$}

Multiple pilot sessions were conducted with research assistants to ensure that the software program was operating correctly. Once software program performance was confirmed, two pilots of the entire procedure were performed.

The experiment was conducted in Istanbul, at Sabanci University's School of Management and Istanbul Technical University's (ITU) Entrepreneurship and Innovation Center (GINOVA). Participants were recruited through fliers hung at both campuses, in courses, and an announcement on GINOVA's website. All participants were paid 20 TL for participation in the experiment and up to $15 \mathrm{TL}$ more for performance. Participants recruited through courses also received 5 course credits (out of 100 total) for their participation. These participants were recorded by the administrators and the number of such participants in each experiment session 
was used as a control variable in the analyses. About half of the experimental sessions had at least one participant who received course credit for participation.

396 participants (132 groups) participated in the three studies. 36 sessions took place at Sabanci University and 97 at ITU. 15 groups were all female, 41 were all male, and 76 were mixed gender.

\section{$\underline{\text { Data Analysis }}$}

During the initial data analysis, we noticed that the three laptops used in the experiment had been out of synchrony in terms of recording times in 9 experiments, leading to misaligned recordings of round starting and ending times. 7 of these occurred in Study 1, 1 in Study 2, and 1 in Study 3.5 were Cyclical triads and 4 were Transitive. We leave these experiments out of the sample in analyses of round completion times and mistakes. We keep them in the sample in analyses of codes.

Graphs and regressions reported in the manuscript were performed on Stata 14 (StataCorp 2015). Multilevel mixed-effects linear regressions are reported for analyses of round completion times in the manuscript (Stata command 'mixed'). These random intercept models estimate separate intercepts for experimental groups. Multilevel mixed-effects negative binomial regressions are used for estimating number of mistakes in each round (Stata command 'menbreg'). Fixed effects regressions produce the same pattern of covariate estimates.

Figure S1. Message sender's screen: Instructions indicate that target image should be conveyed to the message receiver.

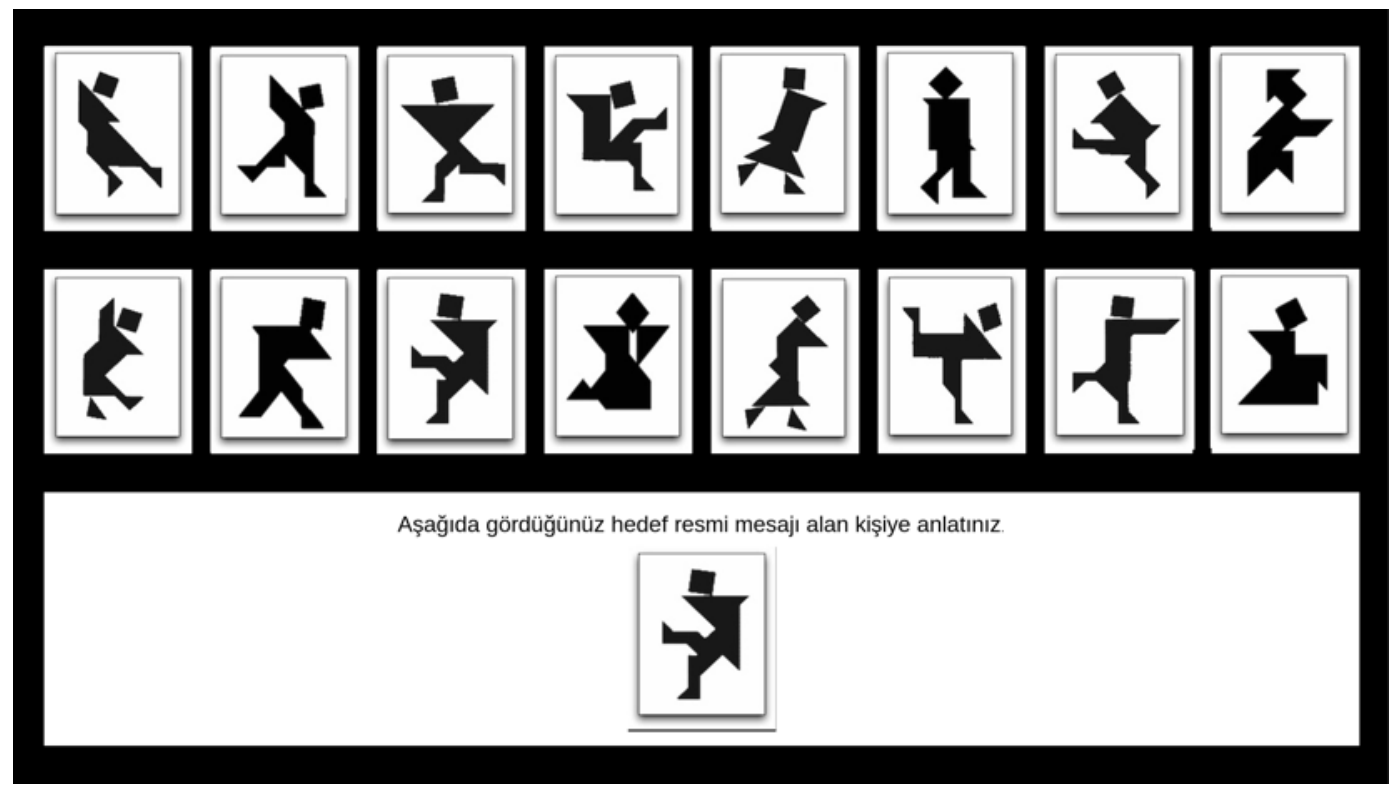


Figure S2. Message receiver's screen: Instructions indicate that target image should be identified based on sender's description.

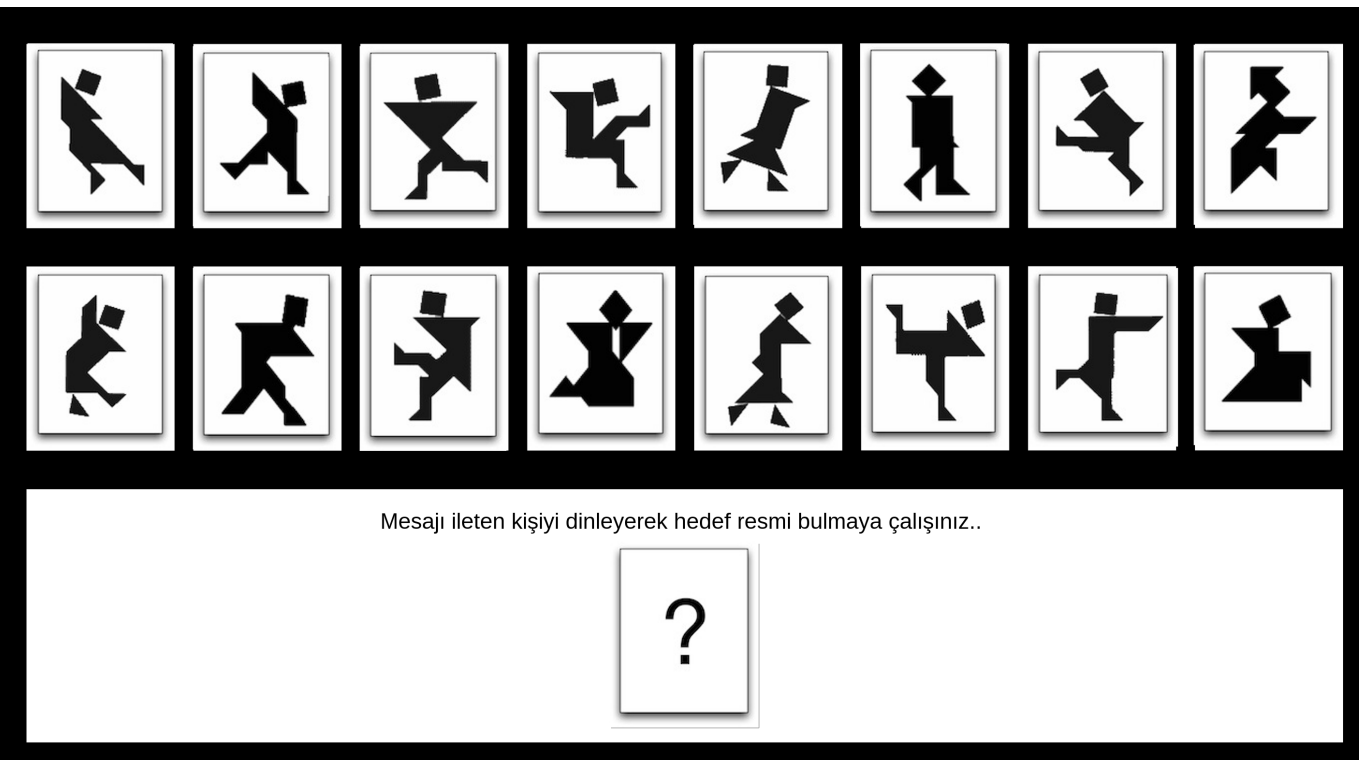

Figure S3. Bystander's screen: Instructions indicate that person should wait.

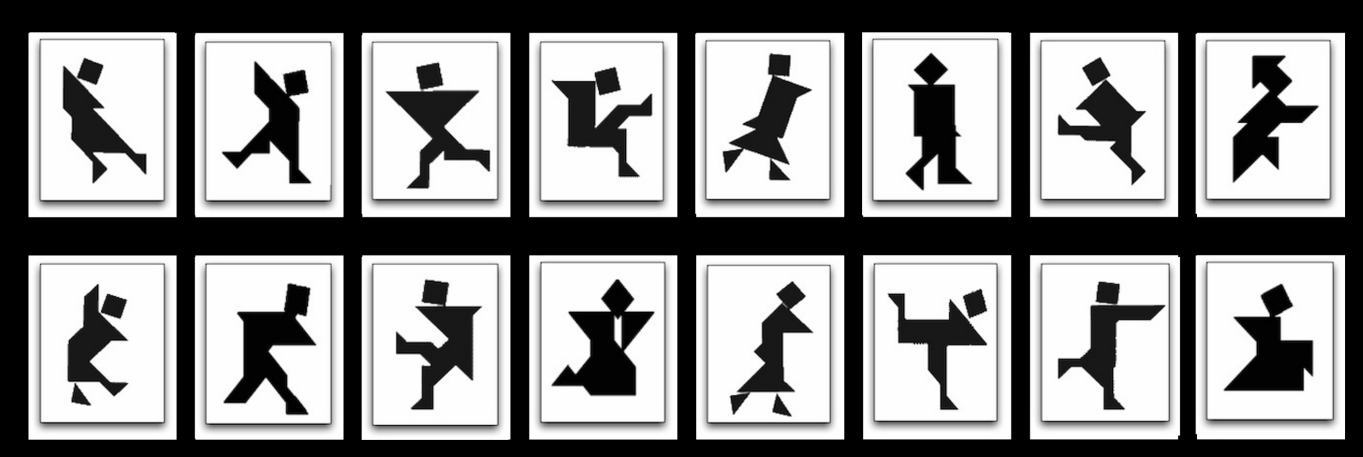

Lütfen sıranın size gelmesini bekleyiniz. 
Table S1. Selected Rounds from Experimental Session Number 983 (Transitive, transparent communication in a triple consisting of friends)

\begin{tabular}{|c|c|}
\hline $\begin{array}{l}\text { Round: } 6 \\
\text { i->k } \\
\text { Time: } 65 \text { seconds } \\
\text { Mistake count: } 2\end{array}$ & $\begin{array}{l}\text { S: Okay... I don't think I can describe this. (Not audible). This also } \\
\text { has a rhombus. It's as if the person is standing, turned to the side } \\
\text { and posing. Errr, how to..? Like a rhombus, the bottom part is like } \\
\text { a triangle but it's like a rocket going up. Think about it like that. } \\
\text { Straight up. Imagine that beneath the square a parallel line is going } \\
\text { up like a rocket. (Laughter) } \\
\text { R: Gah! I can't find it. Does it have, like, a hunched back? } \\
\text { S: No, no hunch. Imagine a rocket. When you look at it, it's more } \\
\text { like a rocket than a person. } \\
\text { R: The bottom part... Is it the upper body that's a triangle? } \\
\text { S: Yes, the upper body is a triangle but the lower part... } \\
\text { R: Ok, got it. } \\
\text { S: Okay. }\end{array}$ \\
\hline $\begin{array}{l}\text { Round: } 11 \\
\text { i->k } \\
\text { Time: } 17 \text { seconds } \\
\text { Mistake count: } 1\end{array}$ & $\begin{array}{l}\text { S: Right, I'm starting. Again, it has a head but it's like a rocket. } \\
\text { Imagine something going up like a rocket. } \\
\text { R: Is it going left? } \\
\text { S: It's going left. So... } \\
\text { R: Okay. }\end{array}$ \\
\hline $\begin{array}{l}\text { Round: } 23 \\
\text { i->k } \\
\text { Time: } 9 \text { seconds } \\
\text { Mistake count: } 0\end{array}$ & S: Rocket. Imagine a rocket going up. \\
\hline $\begin{array}{l}\text { Round: } 86 \\
\text { j->k } \\
\text { Time: } 5 \text { seconds } \\
\text { Mistake count: } 0\end{array}$ & S: Rocket. \\
\hline $\begin{array}{l}\text { Round: } 94 \\
\text { i->k } \\
\text { Time: } 7 \text { seconds } \\
\text { Mistake count: } 0\end{array}$ & S: Rocket. \\
\hline $\begin{array}{l}\text { Round: } 114 \\
\text { i->j } \\
\text { Time: } 8 \text { seconds } \\
\text { Mistake count: } 0\end{array}$ & S: Rocket. \\
\hline
\end{tabular}


Table S2. Selected Rounds from Experimental Session Number 1017 (Cyclical, transparent communication in triple consisting of mix of friends and strangers)

\begin{tabular}{|c|c|}
\hline $\begin{array}{l}\text { Round: } 5 \\
\text { k->i } \\
\text { Time: } 33 \text { seconds } \\
\text { Mistake count: } 0\end{array}$ & $\begin{array}{l}\text { S: In this picture, it's like, the figure has a diagonal body. Both feet } \\
\text { are in the air, she/he looks as if she/he jumped while dancing, the } \\
\text { head is inclined. } \\
\text { R: Err, like, the head is inclined and like, not touching the neck. } \\
\text { S: Yes... The body is like a diagonal. } \\
\text { R: Hmm, yes. The feet should be my right and the head should be } \\
\text { to my left. } \\
\text { S: Yes. } \\
\text { R: Then it must be this one. } \\
\text { S: Yes }\end{array}$ \\
\hline $\begin{array}{l}\text { Round: } 19 \\
\text { k->i } \\
\text { Time: } 45 \text { seconds } \\
\text { Mistake count: } 1\end{array}$ & $\begin{array}{l}\text { S: One foot is on the ground, one foot is in the air. The body is } \\
\text { diagonal... } \\
\text { R: Mm hmm... } \\
\text { S: As if she/he is dancing. Like, as if it's Michael Jackson. So like, } \\
\text { the body is diagonal. The arms aren't visible. } \\
\text { R: Errr ... } \\
\text { S: His/her feet... } \\
\text { R: Is there a backward protrusion from his/her waist? } \\
\text { S: There is, yes. } \\
\text { R: Is there a forward protrusion from the shoulder? } \\
\text { S: Not really. } \\
\text { R: The foot that's on the ground isn't flat, right? It's diagonal... } \\
\text { S: No, it's not flat, it's sort of like on its toes. } \\
\text { S: No, that's not the one. No, that's not it. Both feet are close to } \\
\text { the ground, only one is in the air. } \\
\text { R: Is it the one with a diagonal body? The head... The head... } \\
\text { S: Yes, the body is diagonal. } \\
\text { R: The head doesn't touch? } \\
\text { S: That's right, it doesn't touch. } \\
\text { R: Then this should be Michael Jackson. }\end{array}$ \\
\hline $\begin{array}{l}\text { Round: } 26 \\
\text { k->i } \\
\text { Time: } 7 \text { seconds } \\
\text { Mistake count: } 0\end{array}$ & S: Michael Jackson... The diagonal one. \\
\hline $\begin{array}{l}\text { Round: } 102 \\
\text { j->k } \\
\text { Time: } 6 \text { seconds } \\
\text { Mistake count: } 0\end{array}$ & S: Err, Michael Jackson. \\
\hline
\end{tabular}

Note: Third person singular pronouns are un-gendered in Turkish. We use she/he and her/his where the subjects used a third person pronoun. 